Vol. 4, No. 1, 2018

\author{
Yuriy Royko ${ }^{1}$, Oleg Hrytsun ${ }^{2}$, Romana Bura ${ }^{3}$ \\ ${ }^{1}$ Department of Transport Technologies, Lviv Polytechnic National University, \\ 12, S. Bandera Str., Lviv, Ukraine,E-mail: jurij.rojko@gmail.com \\ ${ }^{2}$ Department of Transport Technologies, Lviv Polytechnic National University, \\ 12, S. Bandera Str., Lviv, Ukraine, E-mail: Oleh.M.Hrytsun@1pnu.ua \\ ${ }^{3}$ Department of Transport Technologies, Lviv Polytechnic National University, \\ 12, S. Bandera Str., ELviv, Ukraine, -mail: romana_bura@ukr.net
}

\title{
CHOOSE OF OPTIMAL REGIMES OF TRAFFIC LIGHT CONTROL IN OPERATING ZONE OF PEDESTRIAN CROSSINGS
}

Received: May 24, 2018 / Revised: June 25, 2018 / Accepted: June 26, 2018

(C) Royko Yu., Hrytsun O., Bura R., 2018

\begin{abstract}
On the given stage of motorization level development and increase of traffic flow intensity, with increasing frequency apply to the implementation of intelligent automated systems of traffic control. The quality of their work depends foremost from study of the primary factors of road users, their behavior, including the factor of a person as movement operator, geometric parameters of communication routes, road conditions as movement environment. Such study is held by methods of field research, documentary research and mathematical modelling. Considering transport system, it is necessary to have in mind that we are concerned with the large array of stochastic indicators which, during its normal operation, comply with the normal law of distribution. If the process of traffic flows movement control, including their attachment to the roadway, parameters of which are clearly regulated by standards, is studied relatively in detail, then regularities in pedestrian flows are underexplored only due to the fact that their behavior quite frequently is regulated.

However, enough amounts of mathematical methods of description the different stochastic systems have appeared, based on which it is possible to perform the simulation of road users' behavior, in particular pedestrians.

In this work it is undertaken experimental research on pedestrians' behavior on signaled pedestrian crossings in Lviv city for different functional zones and in different time of day, and also it is investigated dynamic factors in traffic flow with the aim of determination the rational (by duration) regimes of traffic light control, during which the amount and duration of delays in traffic flows and the possibility of accidents commission is reduced, which are the consequence of road users behavior.

The backgrounds of these negative phenomena are: fluctuation of traffic flow intensity, when pedestrian during longtime restrictive signals can start to move on restrictive signal of traffic light, what is unexpected for vehicle driver, especially in nighttime when blinding appears; observation only the demands of normative documents during designing the communication routes what is not always adequate for different functional areas of settlements; absence of distinct regulation of range of traffic light control parameters which would create its optimal regimes considering traffic and pedestrian flows behavior.
\end{abstract}

Keywords: pedestrian flow, traffic flow, traffic intensity, speed of movement, traffic interval, traffic light control, traffic simulation, field research, automated system of traffic control.

\section{Introduction and Problem Statement}

Organization of traffic and pedestrian flow movement in operative zone of signaled pedestrian crossing, and also provision of their safety is multifaceted task. Complexity of solution of this problem is explained by the influence of many factors, in particular psychophysiological, which complicate appliance of mathematical and mechanical methods of description of principles of traffic and pedestrian flows formation on signaled intersections (crossings) [1]. 
However, the problem of provision of facility and safety of pedestrian movement is one of the most responsible and, therewith, not enough developed chapters of traffic management at the moment. The complexity of this task, in particular, is due to the fact that the pedestrian behavior is more difficult to regulate than drivers behavior, and in calculations of control regimes it is difficult to take into account psychophysiological factors with all deviations, which are inherent to certain pedestrian groups [2].

Pedestrian behavior still stays the most dangerous type of road behavior, as they appear to be the lowest protected traffic participant. Road safety on signaled crossings is dependent most of all from discipline of pedestrians. During longtime waiting for allowing signal the probability of crowding the group of pedestrians increases. Pedestrian, being in such situation, at first perceives environment as it is, adjust to it and later sets certain goals and forms interests. The next stage of making a decision is that the pedestrian starts to move in necessary direction, which can cause crossing the road with increased risk on restrictive signal of traffic light $[1,3]$.

Forecasting of pedestrian behavior is an integral part of anticipated reflection of objective course of events in traffic movement. It is proved that frequency of violation of traffic safety requirements by the pedestrians (crossing the roadway on restrictive signal of traffic light) extensively depends from provocative behavior of one of the pedestrians [5]. An important criterion of providing road safety is possibility of simulation the believable pedestrian behavior, as, while moving, pedestrians aspire to reach the destination point as quickly as possible (working and studying goals), or slowly walking (cultural and social goals) [1]. Taking into account these special aspects, the great amount of field and documentary research is necessary, and also simulation with the purpose of improvement the traffic automated control systems in different periods of the day for different functional zones of the city which could, to the full extent, reflect interests of different groups of its participants and ensure quite high level of reliability of transport system functioning by the criteria of safety and losses of time on moving.

\section{Review of Modern Information Sources on the Subject of the Paper}

Researchers P. Buha [1] and Yu. Shelkov [5] confirm that critical time of expectation (time of patient waiting) depends from the range of subjective factors: physical and psychophysiological condition of the pedestrian, target destination and urgency of his movement, adaptation of pedestrian to the movement conditions, time of the day, year, traffic intensity, longitude of the pedestrian crossing etc.

Experience in exploitation of signaled pedestrian crossings shows that as a calculative value of time of patient waiting can be accepted interval in 30-90 sec [1, 3, 6]. For such duration of restrictive signal, the amounts of persons which violate regulated rules in composition of pedestrian flow compose no more than $15 \%$.

Violation by pedestrians the established rules of crossing the road is explained not only by the lack of their discipline, but also by planning drawbacks during choosing the location of the signaled pedestrian crossings $[1,5,7,9]$.

Location of pedestrian crossings is defined by the complex of town-planning requirements, such as: composition of building and its placement towards motorway and district streets of regulated movement; location schemes of streets on road network in city system; public passenger transport movement schemes etc.

During frequent location of signaled pedestrian crossings traffic flow movement proceeds in groups, intervals between which are close to the maximum (critical saturation of traffic flow). Particular importance it has on motorway streets, where time, needed for pedestrian to cross the roadway, sharply increases, which causes the same increasing of traffic delay which, in its turn, reduces their (motorway) capacity. Approximately the distance between pedestrian crossings is recommended to take no less: for motorway streets of citywide importance $-300 \mathrm{~m}$, of district importance $-250 \mathrm{~m}$, and for local movement streets - 150-200 m [1, 5, 6, 8].

The other problem is the situation, connected with the main factors of traffic flow (with the decrease of traffic flow intensity the number of persons, which violate regulated rules, increases), geometric 
parameters of the crossing (with the increase of the length of the path, which is needed for pedestrians to cross, the number of violations of crossing the roadway decreases) and functional location (pedestrians which, in general, do not live on the territory of the city, pay less attention to control means and therefore discipline of their behavior is weaker).

No less important factor, which has influence on pedestrian safety, is pedestrian delay. Based on research, carried out in Ukraine and abroad, a few models are developed for the assessment of pedestrian delays on signaled crossings [10-13]. In recommendations of Highway Capacity Manual [14] for the first time was performed the gradation of levels of service of pedestrian flow for the controlled intersection (table 1), where geometric parameters of road network and also velocity of the movement are taken into account.

Table 1

Levels of service of pedestrian flow on signaled crossings [14]

\begin{tabular}{|c|c|c|}
\hline Level of service & $\begin{array}{c}\text { Delay of regulation, } \\
\text { sec/unit }\end{array}$ & State of movement \\
\hline A & to 10 & $\begin{array}{c}\text { Very short delay. The number of persons, which violate the regime } \\
\text { of traffic light control, is absent }\end{array}$ \\
\hline B & $10-20$ & $\begin{array}{c}\text { Short delay. Almost no one cross the road on restrictive signal of } \\
\text { traffic light }\end{array}$ \\
\hline C & $20-30$ & $\begin{array}{c}\text { Short delay. A few pedestrians violate the regime of traffic light } \\
\text { control }\end{array}$ \\
\hline D & $30-40$ & Long delay. Pedestrians start to cross the road in conditions of risk \\
\hline E & $40-60$ & $\begin{array}{c}\text { Very long delay. A significant proportion of pedestrians cross the } \\
\text { road on restrictive signal of traffic light }\end{array}$ \\
\hline Fore than 60 & $\begin{array}{c}\text { Very long delay. Almost every pedestrian crosses the road in } \\
\text { conditions of risk }\end{array}$ \\
\hline
\end{tabular}

So, pedestrian delay is a quantitative measure for determination of the level of service, and also one of the criteria of evaluation the effectiveness of functioning of controlled intersection (crossing) in general.

\section{Objectives and Problems of Research}

Object of research - traffic movement in operative zone of signaled pedestrian crossings, which are placed in different functional zones of the city.

Purpose of research - determination of rational (safe) regimes of traffic light control in operative zone of signaled pedestrian crossings because of which, independently from pedestrian behavior and dynamic features of vehicles in traffic flow, the highest level of road safety is reached, by reducing rejections (minimization of violations on the restrictive signals of traffic light and increasing the time of adaptation of vehicle drivers to such violations).

For the achievement of the set aim it is necessary to perform such tasks: 1) to analyze the main research methods of pedestrian behavior on the crossings depending on road conditions, characteristics of traffic flow and regimes and parameters of control; 2) to assess the main results of investigation the pedestrian behavior depending on functional zone of the city, where pedestrian crossing is located; 3 ) to substantiate the criteria for determination the time parameters of delays of road users in operative zone of pedestrian crossings; 4) to determine the rational regimes of control considering characteristics of traffic flows and pedestrian behavior.

\section{Materials and Methods of Research}

Standards and technical documentation from the investigated problem is represented by appropriate State standards (SSTU) $[15,16]$ and State building regulations (SBR) $[17,18]$. By them the requirements to the designing of the crossings under different planning schemes are setting, and also criteria of implementation and application of traffic light control. These criteria are determined on the basis of the justification of economic factors, which take into account the costs of the implementation of traffic light control, time losses by pedestrians during the movement from one point to another with the necessity of crossing signaled pedestrian crossings, traffic and pedestrian delays in zones of their contact. All these factors are summed up to the one system task - choosing the safe regimes of traffic light control in operative zone of signaled pedestrian crossings. 
For the control of traffic flow, justification of implementation of compulsory traffic light control is strictly regulated in [15], and as for pedestrian flows, there exists such condition: if the intensity of traffic flow is more than 600 auto/hour, and for the streets with dividing strip is 1000 auto/hour - with the number of pedestrians on the crossing more than 150 persons/hour or high accidence on the crossing ( 3 and more accidents with the pedestrians per year) it is necessary to build off-street crossing. In case when traffic flow intensity increases and reaches to the values given in [15], traffic organization on the intersection in one level can be possible only with the use of traffic light control.

At the same time affirmations of Russian researchers often are contradictory. They suggest implementing traffic light control during the total intensity of traffic flow movement in all directions from 800 to 3000 units/hour. So, V. Cherepanov [19] suggests implementing traffic light control with the intensity of traffic flow movement in every direction more than 500-600 units/hour. M. Fishelson [20], during assessment the criteria of implementation of control regime, takes into account the condition of safe crossing by pedestrians the roadway and recommends to implement traffic light control with the intensity of traffic flow movement 100-250 auto/hour on every lane or during the total traffic-pedestrian intensity over 1750 units/hour.

V. Sosiants, D. Samoilov, V. Yudin [21] consider that it is necessary to implement traffic light control during the intensity of the movement over 800 auto/hour in all directions or on the basis of provision the safety of pedestrian flow movement, intensity of which is no less than 300 persons/hour during 8 hours, herewith traffic intensity should be no less 600 auto/hour.

V. Vladimirov [22] considers that the basis for implementation the traffic light control is provision of safe conditions for crossing the pedestrians, and also minimization of vehicle delays before the crossing. Recommendations in works [21] and [22] about safe crossing the roadway by pedestrians coincide, but they have wide range of dispersion in comparison with recommendations given in work [20]. So, for example, with the width of road in $12 \mathrm{~m}$ the critical intensity of vehicle movement, according to V. Vladimirov, is 400 auto/hour, and according to M. Fishelson - is 220 auto/hour.

During consideration the issue of determination of cycle duration it is necessary to choose appropriate criterion of traffic light control, which defines its effectiveness. Existing methods of determination the duration of traffic light cycle are based only on evaluation of traffic delays or the duration of vehicle queue, which formed before stop-line (the main delays), but they do not take into account the minimization of pedestrian delays.

English specialist F. Webster proposed method of calculation of traffic light cycle $\left(T_{C}\right)$ duration, which is based on minimization of traffic delays and takes into account occasional arrival of vehicles to stop-line:

$$
T_{C}=\frac{1,5 \cdot T_{t}+5}{1-\sum_{i=1}^{n} y_{i}},
$$

where $T_{t}$ - sum of transitional time, sec; $y_{i}$ - phase coefficient in $i$-phase of control (maximum among ratios of traffic intensity during observed period to the saturation flow (critical capacity) in certain direction of $i$-phase of control); $n$ - number of phases in control cycle.

The main restrictions during the calculation of traffic light control regime is minimum and maximum permissive cycle duration, minimum duration of green light for traffic flow and maximum duration of red light for pedestrian flow. So, for the case, when on all approaches to the intersection exists no more than two lanes, it is recommended the maximum value of the cycle to take equal to $90 \mathrm{sec}$; in case of large intersection this parameter can be reached to $120 \mathrm{sec}$ [24].

A lot of researchers in empirical way set the values of time frames of traffic light cycle duration. So, Yu. Vrubel [6] considers that the duration of cycle for two-phase control should set no less than 70 sec; for three-phase - no less than $90 \mathrm{sec}$; for four-phase - no less than $110 \mathrm{sec}$.

Restriction, which is laid upon the value of minimum duration of traffic light cycle (in recommendations no less than $25 \mathrm{sec}$ ), is due to the fact that during the short duration of cycle in traffic flow low capacity is observed, start delays increase, and fuel consumption is large [25]. 
Duration of restrictive signal for pedestrian flow should not exceed $40 \mathrm{sec}$, in other case sharply increases the possibility of violation the rules of traffic movement (RTM) by pedestrians. Minimal possibility of violation the RTM by pedestrians is achieved during the duration of red signal less than $10 \mathrm{sec}$ [26].

It is proved that traffic and pedestrian intensity changes not only during the day, but also during more short time intervals. Not taking into account this factor causes the occurrence of over-saturated (cycle duration is smaller than optimal value) or under-saturated phases (cycle duration is bigger than optimal value) on certain directions of controlled intersection.

So, determinations of parameters of traffic and pedestrian flows on controlled intersections (crossings) lie in receiving calculative values of ranges, which are used for designing traffic light object. Regime of operation of traffic light control in this case depends from location of pedestrian crossing; traffic and pedestrian movement intensity, pedestrian`s speed of movement; availability of sufficient area for crowding of pedestrians, which are waiting the permissive signal of traffic light. Clear understanding of pedestrian behavior on signaled crossings in mixed traffic conditions is necessary during infrastructure arrangement for service of pedestrian flow, and also for increasing safety of their movement.

Based on this, the necessary research for initiation the model of vehicle drivers' behavior during the passing through the intersection and pedestrians during the crossing the road. The result of such modeling would be the reproduction of the real behavior of drivers and pedestrians in real road conditions, and also opportunity of its (behavior) change depending from influence factors in the system "traffic flows - road conditions".

Method of definition the time of patient waiting of pedestrians under different control regimes and road parameters. If the delay of pedestrians can be determined experimentally by direct measurements, hence for quantitative expression of time of patient waiting it is necessary to conduct numerous investigations of the process of crossing the roadway by pedestrians. It will allow differentiating factors, which directly, in one degree or another, have influence on determination of time of patient waiting of pedestrian and choose of safe regimes of traffic light control [1].

Native method of calculation of time of patient waiting of pedestrians is quite simple. For this method, basic value of time of patient waiting is determined with the taking into account the duration of restrictive signal for pedestrians, traffic intensity and road width.

Factors, which have impact on values of time of patient waiting of pedestrians, have impact also on changing the regime of traffic light control. Thus, none of the methods of time of patient waiting of pedestrians does not take into account functional location of the crossing related to the objects of attraction and weather-climate conditions, which determine the level of observance by them the regulated rules and possibility of their crossing on restrictive signal. Thus maximum number, which can pass the crossing for one cycle at a given duration of restrictive signal of traffic light, depends from the speed of pedestrians and time intervals between vehicles.

Let's consider the method of pedestrian behavior during their crossing the road, which is used for measurement of time of patient waiting of pedestrians.

At the first stage of work, using the method of field research, it is necessary to determine geometric parameters of the crossing and the duration of the main and restrictive signals of the traffic light; the number of pedestrians, which cross the road directly through the crossing in such sequence: when enabled the permissive signal to register the number of pedestrians, which cross on one of the approaches; to note the moment of crossing of the last pedestrian; register the number of accumulated pedestrians during restrictive signal of the traffic light; register the number of persons, which pass during the restrictive signal of the traffic light; when enabled the permissive signal to register vehicles, which pass the stop-line on the approach of the intersection.

At the second stage it is necessary to determine: type of regulation (fixed-time or adaptive); in which functional zone of the city the intersection is placed; weather-climate conditions of movement during the investigation.

At the next stage it is necessary to determine the speed, with which pedestrians cross the road. For this point it is necessary to measure the width of the roadway and using stopwatch to note the time, which pedestrians (men, women) spend to make cross the roadway. Experiment is need to be repeated no less 
than 20 times for different age categories of pedestrians (younger, middle and senior age) on every of investigated crossings and to determine the average speed of pedestrian movement. For measurements the protocol is used, which is shown in Fig. 1.

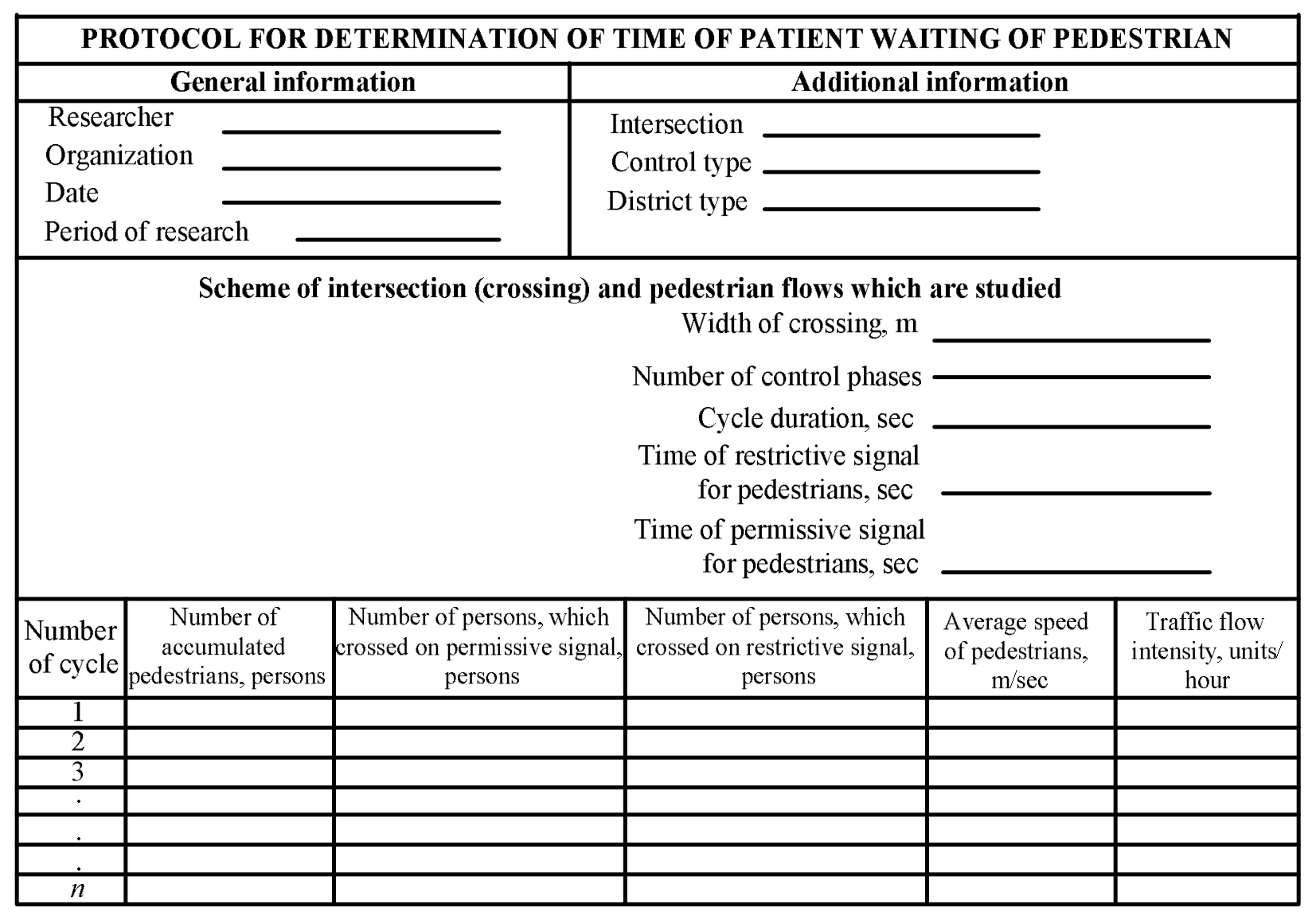

Fig. 1. Protocol for determination of time of patient waiting of pedestrians

Based on this, a number of studies have been conducted, which will be able to objectively evaluate the using of the traffic light signals during the crossing the roadway by pedestrians in different functional zones of the city in conditions of risk, which depends from two factors - traffic flow intensity and crossing length. Complex comparison of obtained results will give an opportunity to adequately evaluate pedestrian behavior during the pass on restrictive signal of traffic light depending on traffic light control regime and geometric parameters of road network.

Method of investigation of delays in traffic flows depending from control parameters. Despite the fact that analytical and experimental research on vehicle delays on signaled intersections (crossings) had been performing during long period of time, still have not been received such exact results as in other chapters of queueing theory. The reason is the fact that microscopic models of description the movement of vehicles were not always reviewed as stable process because periodic changes are observed in it. So we can forecast only approximate analysis of situations. Another reason is the fact that vehicles which arrive to the stop-line have already been exposed to the range of signaled intersections through which they have passed. That is why everything is limited to multiphase queueing system in which it is complicated determine even characteristics of vehicle arrival [24].

For this reason, let's describe approximate methods of investigation of delays in traffic flows depending from traffic light control parameters. Traffic flows delay is closely connected with such factors as: queue length, traffic intensity, traffic capacity, control regime parameters.

There exists the range of different methods of measurement the volume of traffic delay on signaled intersection. Traffic delay can be determined with the help of: observation the behavior of vehicle in the 
flow; investigation of vehicle motion trajectory; calculation the number of vehicles which arrive and depart from the intersection in every cycle.

Method, described below, is based on the direct determination the number of vehicles in the queue before intersection. This method is appropriate for all signaled intersections (pedestrian crossings), traffic intensity on which does not exceed their capacity (it is accepted to take no more than 20-25 automobiles per lane for cycle). For intersections, on which level of service approaches to 1.0, it is complicated to use this method due to the fact that more researchers are needed. In this case it is necessary to use other methods of research.

Given method does not provide an opportunity to determine directly the delay during acceleration and deceleration of vehicle movement, which is quite hard to perform without special equipment. But it allows to measure quite precise value of traffic delay.

In this method are used factors which correct mistakes, connected with the usage of such quite simple method and, in particular, mistakes, connected with the acceleration and deceleration of movement. Factor that takes into account acceleration and deceleration is the function of average value of vehicles in the queue in every cycle from the speed of vehicle free movement (in motion unhampered).

In Fig. 2 is given the form for measurement the traffic delay on intersection, which can be used for investigation. Before the start of the pursuance of the investigation, it is necessary, by field research, to determine the speed of vehicle free movement on signaled intersection.

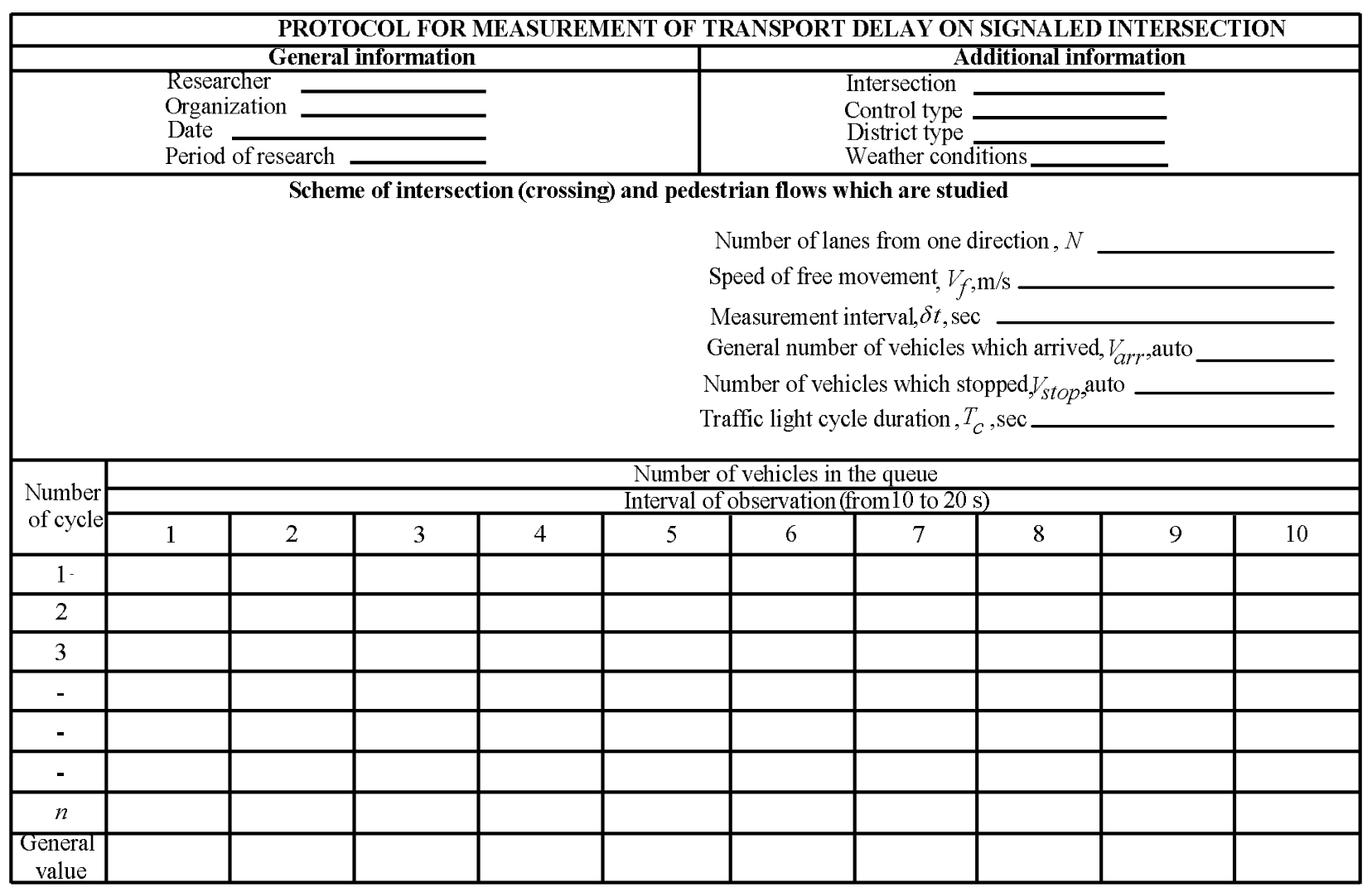

Fig. 2. Protocol for measurement of transport delay on signaled intersection

The speed of free movement is the speed of vehicle which arrived to the intersection on green signal of traffic light (in the absence of queues) and passed it without obstacles. To determine this speed, it is necessary to know the parameters of intersection and time during which the vehicle passes it. At this time, measurements are necessary to be held in such part of the intersection where the most convenient motion through the intersection is provided. As a rule, such section is chosen in the middle part of intersection [24].

The survey should start at the beginning of red signal for given group of vehicles. Herewith, it is desired that in the beginning of investigation should be absent the remained queue of vehicles which have 
not left the intersection during previous cycle of traffic light control. In another case the number of vehicles which have not left the intersection during previous cycle of traffic light control should be excluded from the next measurements. Two researchers should take part in investigation.

The first researcher should perform the next steps [24]:

1) It is necessary to keep under steady watch the last stopped vehicle in the queue in every lane during the whole period of survey for every cycle of control. Here, it is also necessary to consider those vehicles which arrived during the green signal, but were forced to stop due to the fact that the vehicle which arrived too late to pass the intersection stands ahead.

2) Because of instant intervals from 10 to $20 \mathrm{sec}$, it is necessary to note the number of vehicles in the queue (using digital timer) and to put them into appropriate cell of protocol (Fig. 2). As an instant interval should be chosen the number, on which the duration of cycle control is divided exactly (i.e. if the cycle is 120 secs, then measurement interval may be equal 15 or 20, but not $14 \mathrm{sec}$ ). Herewith in the queue should be included all vehicles which have not passed the stop-line in time, taking into account the last vehicle in the queue, determination of which is described in paragraph 1. For the pass of stop-line by the vehicle, which moves straight, is accepted the moment of pass over the stop-line of its rear bumper. For the pass of stop-line by the vehicle, which moves right or left, is accepted the moment of pass of its rear bumper of conflict zone with the opposite traffic or pedestrian flow. It is necessary to admit, that to the composition of queue often are included vehicles which had time to gather speed of free movement, but still have not passed the stop-line.

3 ) In the end of survey period, it is necessary to continue the count of vehicles in the queue until chosen as the last vehicle will not pass the stop-line.

The second researcher should perform the next acts. During the whole period of survey, it is necessary to count separately the general number of arriving vehicles and the general number of arriving vehicles in which traffic delay took place one or more times. At this time cars, which stopped several times, should be taken into account only one time [25].

It is also necessary to summarize all values in columns, and then summarize received values. The value of this sum would be general amount of vehicles in the queue during the whole period of survey. The duration of execution the measurement for every lane on the intersection - minimum 10 control cycles.

To perform the calculation of factors of traffic delay on intersection for the next method:

a) determine the share of vehicles which stopped before the stop-line on the intersection [24]:

$$
p_{\text {stop }}=\frac{N_{\text {stop }}}{N_{\text {arrive }}},
$$

where $N_{\text {stop }}$ - number of vehicles which stopped before stop-line, auto.; $N_{\text {arrive }}-$ general amount of arrived vehicles, auto;

b) number of vehicles which stopped for 1 control cycle [24]:

$$
n_{v e h}=\frac{N_{\text {stop }}}{n_{l} \cdot n_{c}},
$$

where $n_{l}$ - number of lanes from given direction; $n_{c}$ - number of investigated control cycles;

c) the next step is the determination of duration the stay of one vehicle in the queue (average vehicle delay in the queue) (sec/auto) [24]:

$$
d_{1}=\delta t \cdot \frac{N_{\text {observ }}}{N_{\text {arrive }}} \cdot 0.9
$$

where $\delta t$ - measurement interval, sec; $N_{\text {observ }}$ - general number of vehicles in queue for observation period (determines as sum of values of vehicles from measurements of measurement form), auto.; 0.9 empiric passenger car equivalent. Passenger car equivalent 0.9 is used for considering possible mistakes, connected with "human" factor, with which estimated value of delay, as a rule, can be overestimated in comparison to the present value of control value on the given element of the intersection;

d) delay of vehicle from the acceleration and deceleration is determined by equation (sec/auto) [24]:

$$
d_{2}=p_{\text {stop }} \cdot k_{1}
$$

where $k_{1}$ - factor which takes into account acceleration and deceleration of vehicle (Table 2). 
Corrective coefficient for determination of traffic flow on the intersection [24]

\begin{tabular}{|c|c|c|c|}
\hline \multirow{2}{*}{$\begin{array}{c}\text { Speed of vehicle free } \\
\text { movement, km/hour }\end{array}$} & \multicolumn{3}{|c|}{ Number of vehicles in queue, units } \\
\cline { 2 - 4 } & $\leq 7$ vehicles & $8-19$ vehicles & $20-30$ vehicles \\
\hline$\leq 60$ & +5 & +2 & +1 \\
\hline$>60-71$ & +7 & +4 & +2 \\
\hline$>71$ & +9 & +7 & +5 \\
\hline
\end{tabular}

Using data of Tab. 2, it is necessary to determine corrective coefficient due to the speed of free movement in given area and the number of vehicle stops per lane for one control cycle. This coefficient considers delay, connected with acceleration and deceleration of vehicles which cannot be considered during performing the measurements manually.

e) general traffic delay per one vehicle will comprise (sec/auto) [24]:

$$
d=d_{1}+d_{2} \text {. }
$$

In case when an observed intersection is present adaptive control with alternation of cycle duration and control phases, as measurement interval $\delta t$ can be chosen the most convenient value in terms of traffic intensity and chosen place of conducting research.

Observation on locality should finish in the moment when in the end of measurement interval queue still remains. Herewith into account are taken only those vehicles which arrived to the intersection during given interval.

\section{Main Material Presentation}

From the results of processing the results of field research, presented in method of determination of time of patient waiting of pedestrians in different control regimes and roadway parameters it is defined the time which pedestrians spend on crossing the road depending on its width and pedestrian flow intensity (Fig. 3).

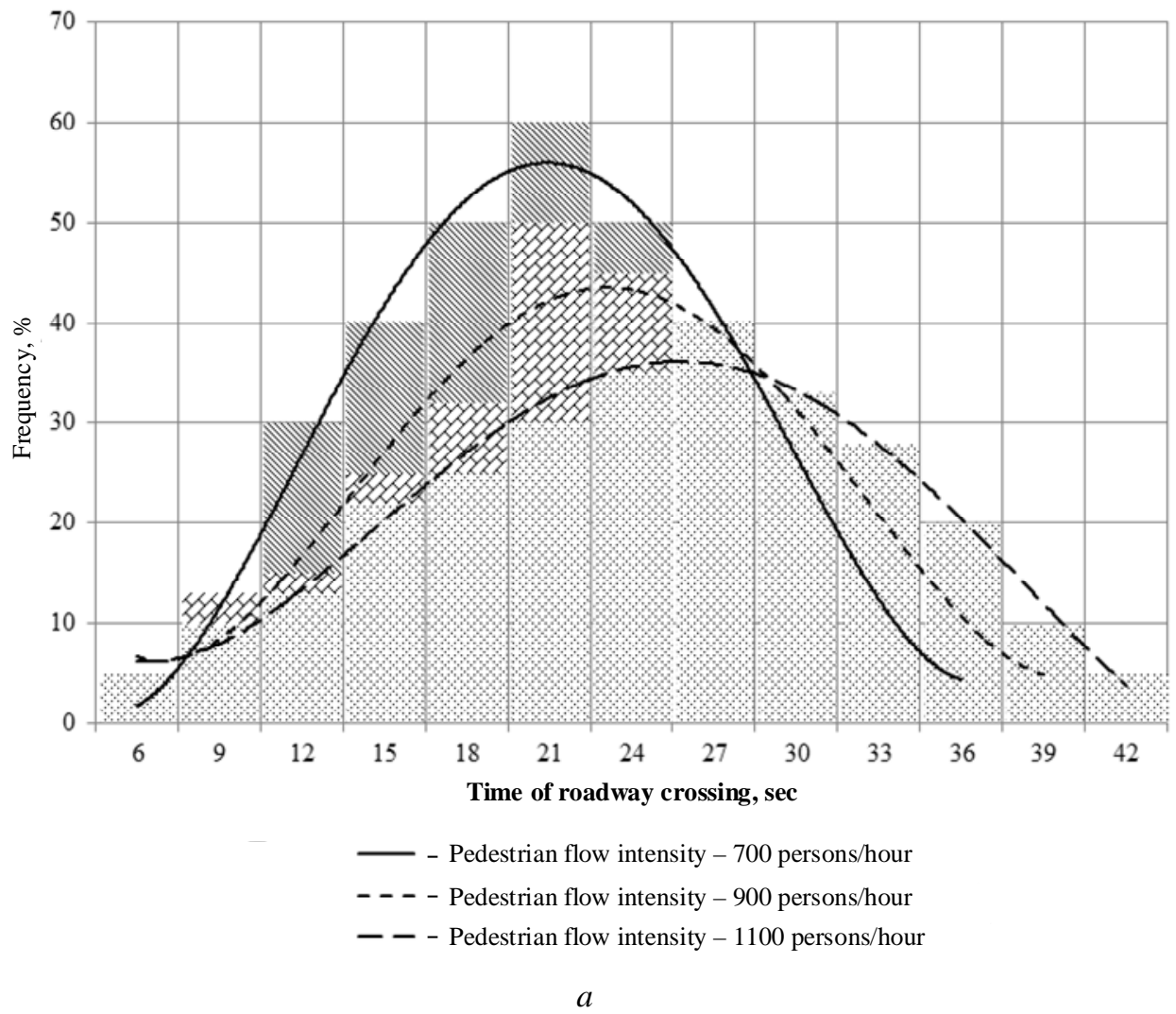

Fig. 3. Distribution of average time which pedestrians spend on crossing the roadway: a - suburban zone (zone near suburban railway station), roadway width $28 \mathrm{~m}$; 


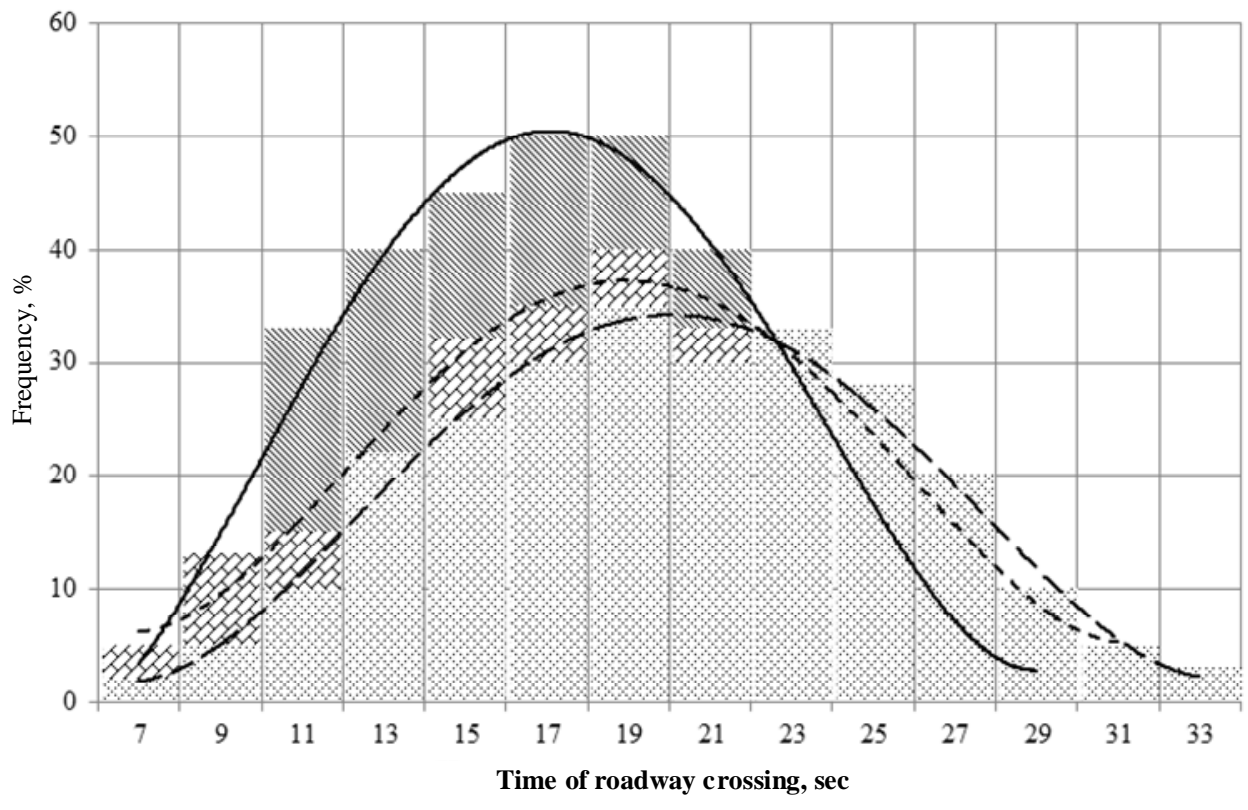

- - Pedestrian flow intensity - 800 persons/hour

- - - - Pedestrian flow intensity -1150 persons/hour

- - - Pedestrian flow intensity - 1400 persons/hour

$b$

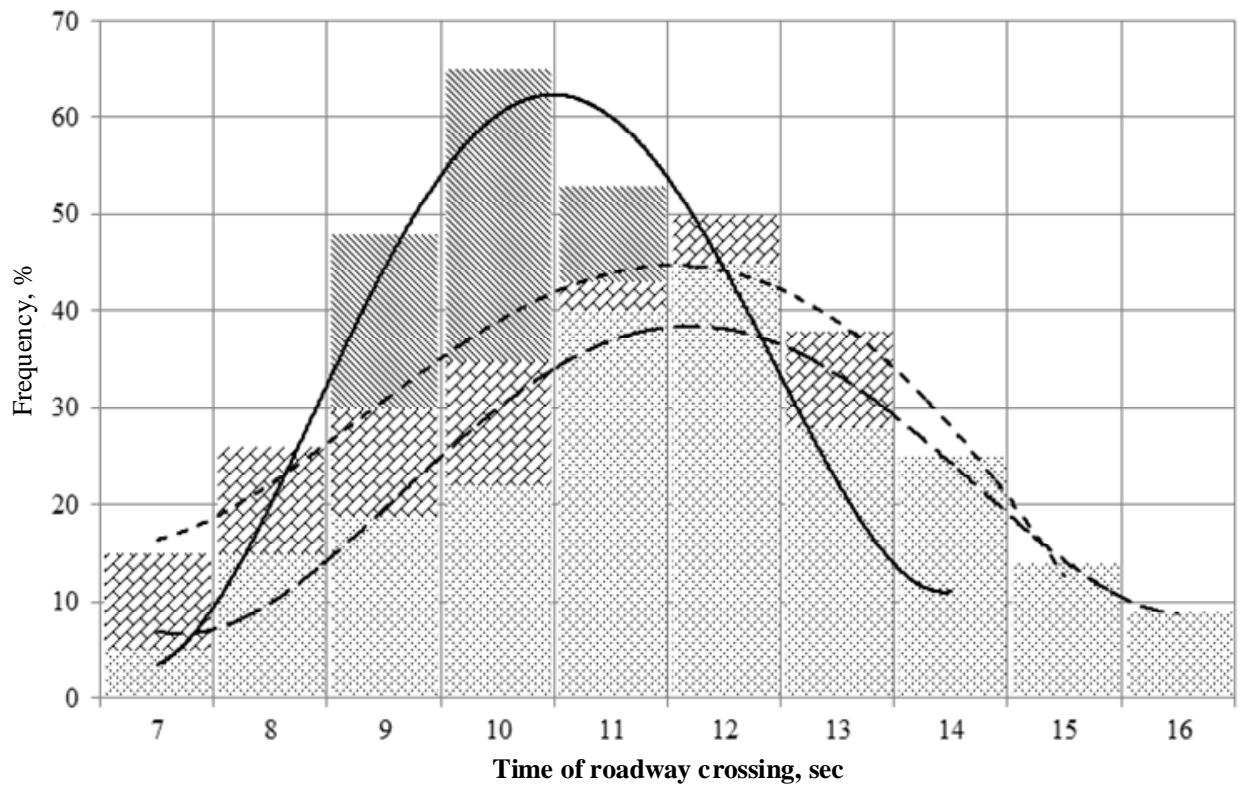

— - Pedestrian flow intensity -400 persons/hour

- - - Pedestrian flow intensity -500 persons/hour

- - Pedestrian flow intensity -650 persons/hour

$c$

Continuation of the Fig. 3. Distribution of average time which pedestrians spend on crossing the roadway: $b$-central zone, roadway width $18 \mathrm{~m}$; $c$ - residential zone, roadway width $18 \mathrm{~m}$

Analyzing results of this research, we can confirm that the most significant decrease of speed of pedestrian movement is observed due to the condition when its intensity in both directions on the crossing increases. So, if compare two pedestrian crossings with the same width $(18 \mathrm{~m})$, one of which is located in residential zone (Fig. 3, c), and another in central zone (Fig. 3, b), then with the increase of intensity from 
400 to 800 persons/hour, time spent by pedestrians for crossing increases in about $60 \%$, which is caused by a sharp fall of speed of both flows (direct and upcoming) after achievement the middle of intersection and also due to the fact that accumulated group of pedestrians which wait for permissive signal with its turning on did not start the crossing immediately. Herewith, smaller by intensity pedestrian flows have smaller range of time which is spent on crossing: with intensity of 400 persons/hour frequency in distribution over $60 \%$ while with intensity of 800 persons/hour - is approximately $50 \%$. Here it is also necessary to point that in central zone (Fig. 3, $b$ ), where concurrent and counter flow are approximately the same, the amount of frequency is smaller than in residential area (Fig. 3, c). Similar tendency can be observed near suburban railway station where with increase of pedestrian flow intensity its stability decreases (frequency with intensity of 700 persons/hour increases from about $56 \%$ to about $37 \%$ with intensity 1100 persons/hour), and average time, necessary for pass of the crossing.

During the performance of field research, the compulsory condition was fixation those pedestrians which crossed the investigated pedestrian crossing in time when permissive signal was turned off. Results of such measurements are described in Fig. 4.

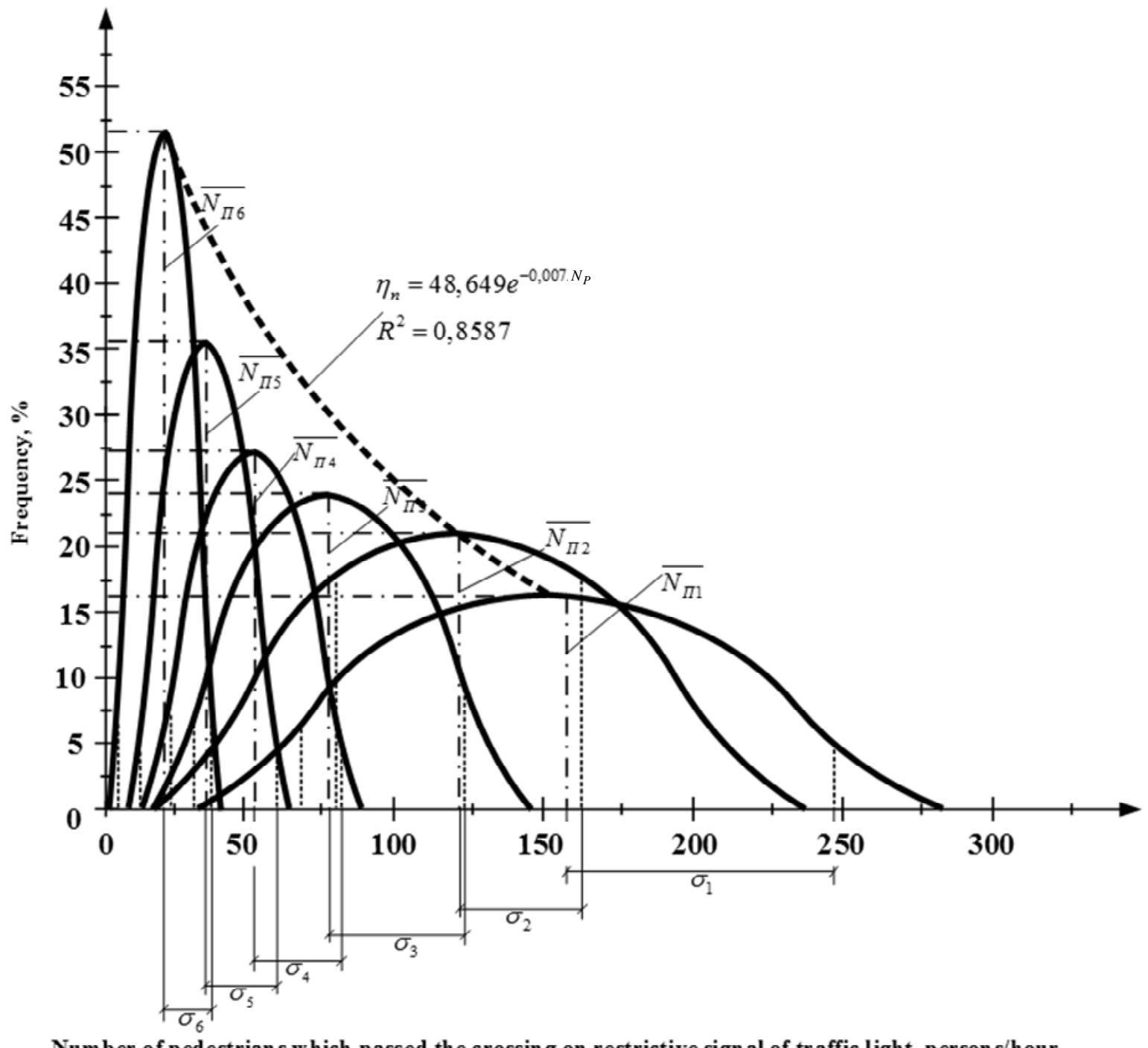

Number of pedestrian s which passed the crossing on restrictive sign al of tr affic light, person s/hour

Fig. 4. Distribution of the amount of violations by pedestrians the requirements of traffic light at different width of crossing: $1-4.0 m ; 2-7.5 m ; 3-11.25 m ; 4-15.0 m ; 5-18.75 m ; 6-22.5 m$, where $\sigma_{i}$ - mean square deviation the number of pedestrians which passed the crossing on restrictive signal of traffic light; $N_{P i}-$ statistical expectation the number of pedestrians which passed the crossing on restrictive signal of traffic light 
As it is seen from Fig. 4, on signaled pedestrian crossings through the narrow roadway the number of pedestrians, which neglect road safety conditions, is larger in comparison with wide roadway. Analysis showed that this phenomenon appears from several reasons:

- interval between groups of vehicles in the flow on streets with controlled movement is frequently considered by pedestrians safe for accomplishment the maneuver;

- if on the intersection operates two-phase or three-phase cycle of traffic light control, then waiting time of permissive signal for pedestrians is long and they make a decision about crossing the roadway in time when movement are making turning traffic flows;

- with the increase of number of pedestrians which accumulated near traffic light, waiting for permissive signal of traffic light, the most frequently appears situation when one of pedestrians makes a decision about crossing in risk conditions and after him follows some group of other pedestrians;

- pedestrian which waited for permissive signal on crossing in large group and have not time because of the size of this group to make a crossing on permissive signal of traffic light, will try to realize it under any circumstances.

Those particular factors, which frequently defined the model of pedestrians' behavior during field research, are the reason of such distribution time for implementation of crossing (Fig 3) and distribution of violation of road safety conditions (Fig. 4). During these researches they were taken into account in order to estimate the real need for time of pedestrian flow movement, and also with the aim to simulate traffic flow delays in conditions of account the existing methodical approaches and compare their possible values in situations, when specified necessity of pedestrians would be realized.

With this aim in system of mathematical modelling according to existing methods and in system of simulation modelling (software environment VISSIM) corrective coefficient was entered, which takes into account pedestrians behavior with realization of their necessity and is based on parameters of time of patient waiting, amount of pedestrians' flow intensity, location of signaled pedestrian crossing (functional zone of the city), traffic flow intensity, traffic light control regime. Received results are described in Tab. 3.

Table 3

\section{Results of investigation of time loss of traffic flow on intersections which are located in different functional zones of the city including pedestrian behavior}

\begin{tabular}{|c|c|c|c|c|c|c|c|c|c|c|c|}
\hline & \multirow[b]{2}{*}{ 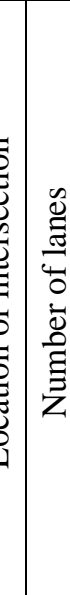 } & \multirow[b]{2}{*}{ 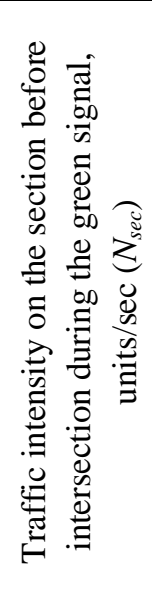 } & \multirow[b]{2}{*}{ 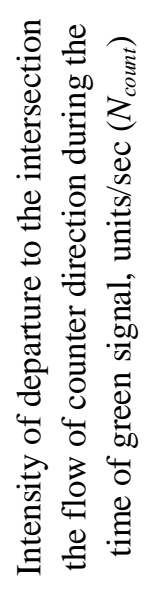 } & \multirow[b]{2}{*}{ 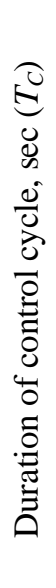 } & \multirow[b]{2}{*}{ 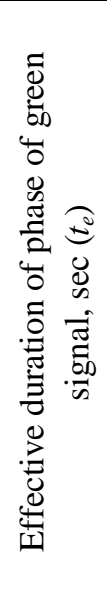 } & \multirow[b]{2}{*}{ 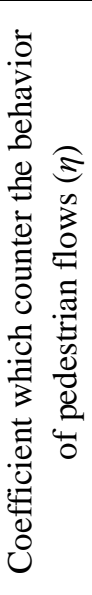 } & \multirow[b]{2}{*}{ 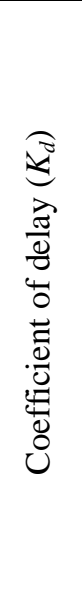 } & \multirow[b]{2}{*}{ 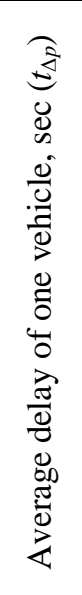 } & \multicolumn{3}{|c|}{$\begin{array}{l}\text { Time losses of vehicles, hour } \\
\qquad\left(T_{\Delta}\right)\end{array}$} \\
\hline & & & & & & & & & 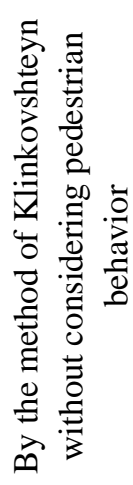 & 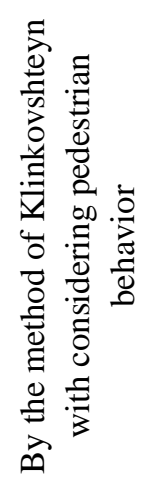 & 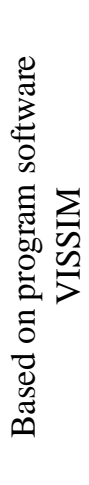 \\
\hline 1 & 2 & 3 & 4 & 5 & 6 & 7 & 8 & 9 & 10 & 11 & 12 \\
\hline \multirow{8}{*}{ 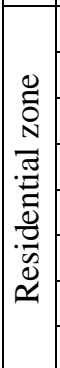 } & \multicolumn{11}{|c|}{ One-way movement } \\
\hline & 1 & 0.13 & 0 & 35 & 32 & 1.18 & 1.18 & 1.50 & 0.19 & 0.22 & 0.36 \\
\hline & 2 & 0.31 & 0 & 44 & 37 & 1.16 & 1.36 & 3.56 & 1.28 & 1.48 & 1.22 \\
\hline & 3 & 0.35 & 0 & 48 & 40 & 1.41 & 1.65 & 4.09 & 1.67 & 2.35 & 2.36 \\
\hline & \multicolumn{11}{|c|}{ Two-way movement } \\
\hline & 1 & 0.22 & 0.02 & 46 & 42 & 1.11 & 1.10 & 1.97 & 0.43 & 0.48 & 0.52 \\
\hline & 2 & 0.36 & 0.03 & 52 & 44 & 1.05 & 1.21 & 4.21 & 1.76 & 1.84 & 1.95 \\
\hline & 3 & 0.58 & 0.04 & 84 & 70 & 1.02 & 1.18 & 7.16 & 4.85 & 4.94 & 3.65 \\
\hline
\end{tabular}


Continuation of the table 3

\begin{tabular}{|c|c|c|c|c|c|c|c|c|c|c|c|}
\hline 1 & 2 & 3 & 4 & 5 & 6 & 7 & 8 & 9 & 10 & 11 & 12 \\
\hline $\mathscr{\Xi}$ & \multicolumn{11}{|c|}{ One-way movement } \\
\hline$\stackrel{\circ}{\mathrm{N}}$ & 1 & 0.13 & 0 & 35 & 32 & 1.37 & 1.36 & 1.50 & 0.19 & 0.26 & 0.42 \\
\hline \multirow{2}{*}{ 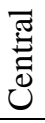 } & 2 & 0.31 & 0 & 44 & 37 & 1.29 & 1.51 & 3.56 & 1.28 & 1.65 & 1.36 \\
\hline & 3 & 0.35 & 0 & 48 & 40 & 1.26 & 1.48 & 4.09 & 1.67 & 2.10 & 2.58 \\
\hline \multicolumn{12}{|c|}{ Two-way movement } \\
\hline \multirow{3}{*}{ 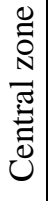 } & 1 & 0.22 & 0.02 & 46 & 42 & 1.21 & 1.20 & 1.97 & 0.43 & 0.52 & 0.76 \\
\hline & 2 & 0.36 & 0.03 & 52 & 44 & 1.18 & 1.36 & 4.21 & 1.76 & 2.07 & 2.54 \\
\hline & 3 & 0.58 & 0.04 & 84 & 70 & 1.15 & 1.34 & 7.16 & 4.85 & 5.57 & 4.21 \\
\hline \multirow{8}{*}{ 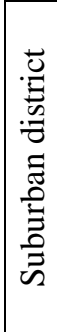 } & \multicolumn{11}{|c|}{ One-way movement } \\
\hline & 1 & 0.13 & 0 & 35 & 32 & 1.53 & 1.52 & 1.50 & 0.19 & 0.29 & 0.48 \\
\hline & 2 & 0.31 & 0 & 44 & 37 & 1.41 & 1.65 & 3.56 & 1.28 & 1.80 & 1.23 \\
\hline & 3 & 0.35 & 0 & 48 & 40 & 1.37 & 1.61 & 4.09 & 1.67 & 2.28 & 2.97 \\
\hline & \multicolumn{11}{|c|}{ Two-way movement } \\
\hline & 1 & 0.22 & 0.02 & 46 & 42 & 1.34 & 1.32 & 1.97 & 0.43 & 0.58 & 0.97 \\
\hline & 2 & 0.36 & 0.03 & 52 & 44 & 1.28 & 1.48 & 4.21 & 1.76 & 2.25 & 2.89 \\
\hline & 3 & 0.58 & 0.04 & 84 & 70 & 1.24 & 1.44 & 7.16 & 4.85 & 6.01 & 5.21 \\
\hline
\end{tabular}

During the simulation was not taken into account intersections, when for turning of traffic flow is provided separate control phase for making the turn. From the results of range of investigations and simulation the quality of intersections which are located in different functional zones, it is set that traffic delay of the same (for geometric parameters) intersections with the same duration of control cycle in suburban zones is bigger than in residential and central at the same intensity of traffic flows. So, in central part of the city traffic flows increase because of large number of pedestrians, pick up and drop offs, maneuvers on automobile parkings. Influence of these factors is less notable in residential zones, distant from center.

Possible explanation to this fact - is hurried rhythm of life in central zone, a habit for a quick ride and more experience of drivers. Truly speaking, this fact is not compulsory and not all research results have confirmed this statement.

In Tab. 3, there are given the results of investigation the time loss of traffic flows on intersections, which are located in different functional zoned of the city.

Graphic interpretation of simulation results is described in Fig. 5.

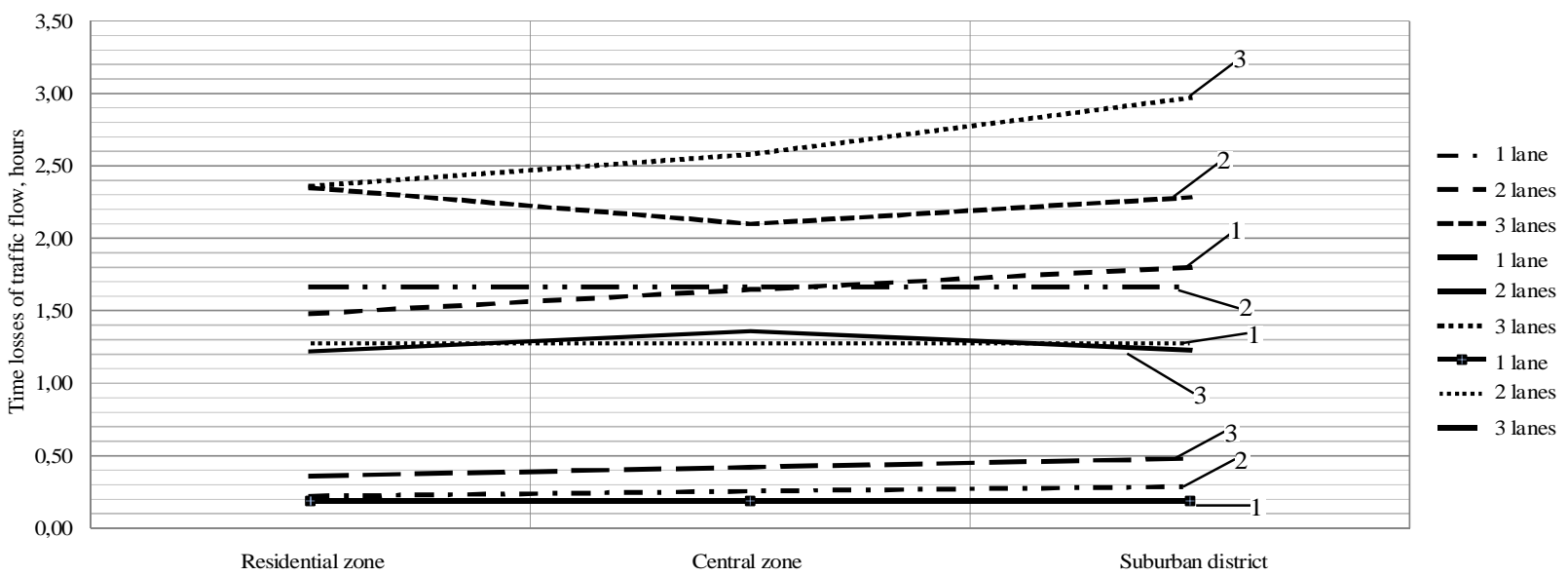

$a$

Fig. 5. Distribution of time losses of traffic flows during an hour on intersections which are located in different functional zones of the city: $a$-at one-way movement; 1 - by the method of Klinkovshteyn without considering pedestrian behavior;

2 - by the method of Klinkovshteyn with considering pedestrian behavior; 3 - based on program software VISSIM 


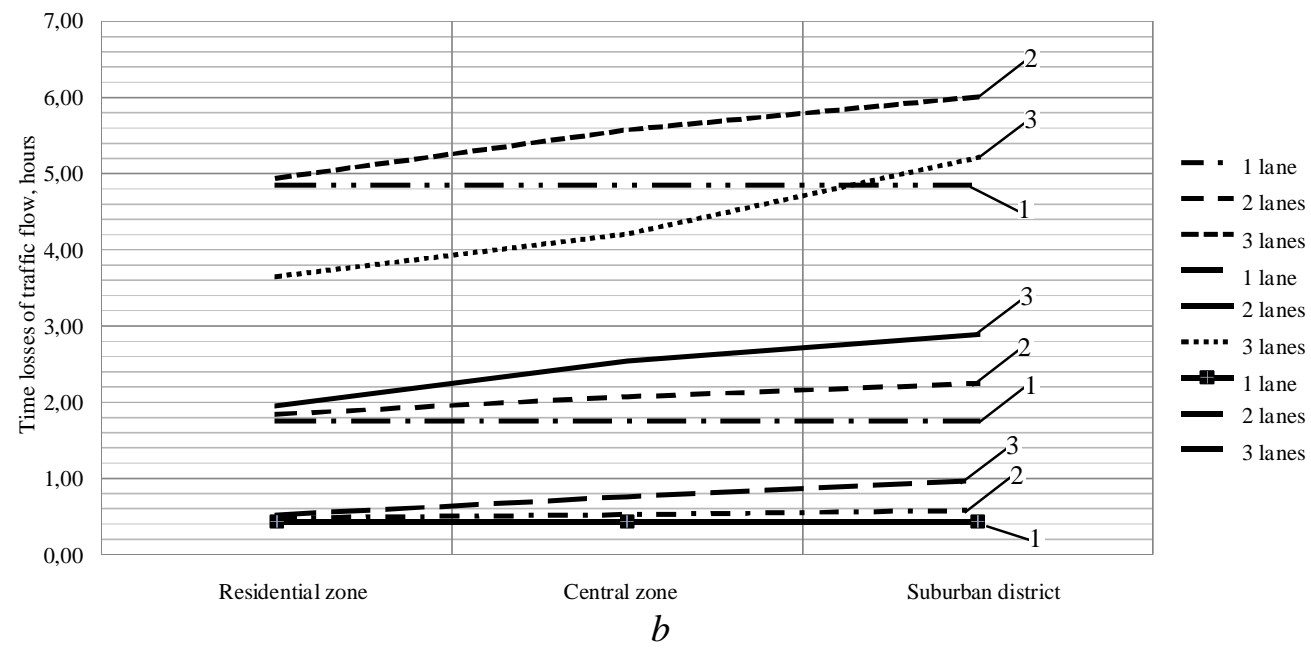

Continuation of the Fig. 5. Distribution of time losses of traffic flows during an hour on intersections which are located in different functional zones of the city: $b$ - at two-way movement; 1 - by the method of Klinkovshteyn without considering pedestrian behavior; 2 - by the method of Klinkovshteyn with considering pedestrian behavior; 3 - based on program software VISSIM

As it is seen from Fig. 5 the most important factor which has influence on the value of traffic delay is the width of the section before intersection (number of lanes). Vehicles which perform the right turn make a great contribution on the value of traffic delay due to the fact that, as a rule, because of the small radius of turn drivers are obliged to lower the speed in comparison to actual on the other lanes. In addition, pass of pedestrian flows in one control phase has impact on intervals between vehicles and complicates the performance of turning maneuver.

For effective planning of signaled crossings on the road network, besides study and simulation of traffic flows, it is necessary to pay attention also to pedestrian flows and analyze pedestrian behavior depending on geometric parameters of roadway, location of the crossing.

At the last stage it is performed simulation of queue length of vehicles relatively stop-line before signaled pedestrian crossing considering equivalent traffic flow intensity and restrictive signal duration, which is determined by the traffic flow intensity of conflict directions and the necessity of pedestrian flows. Simulation results are given in Fig. 6.

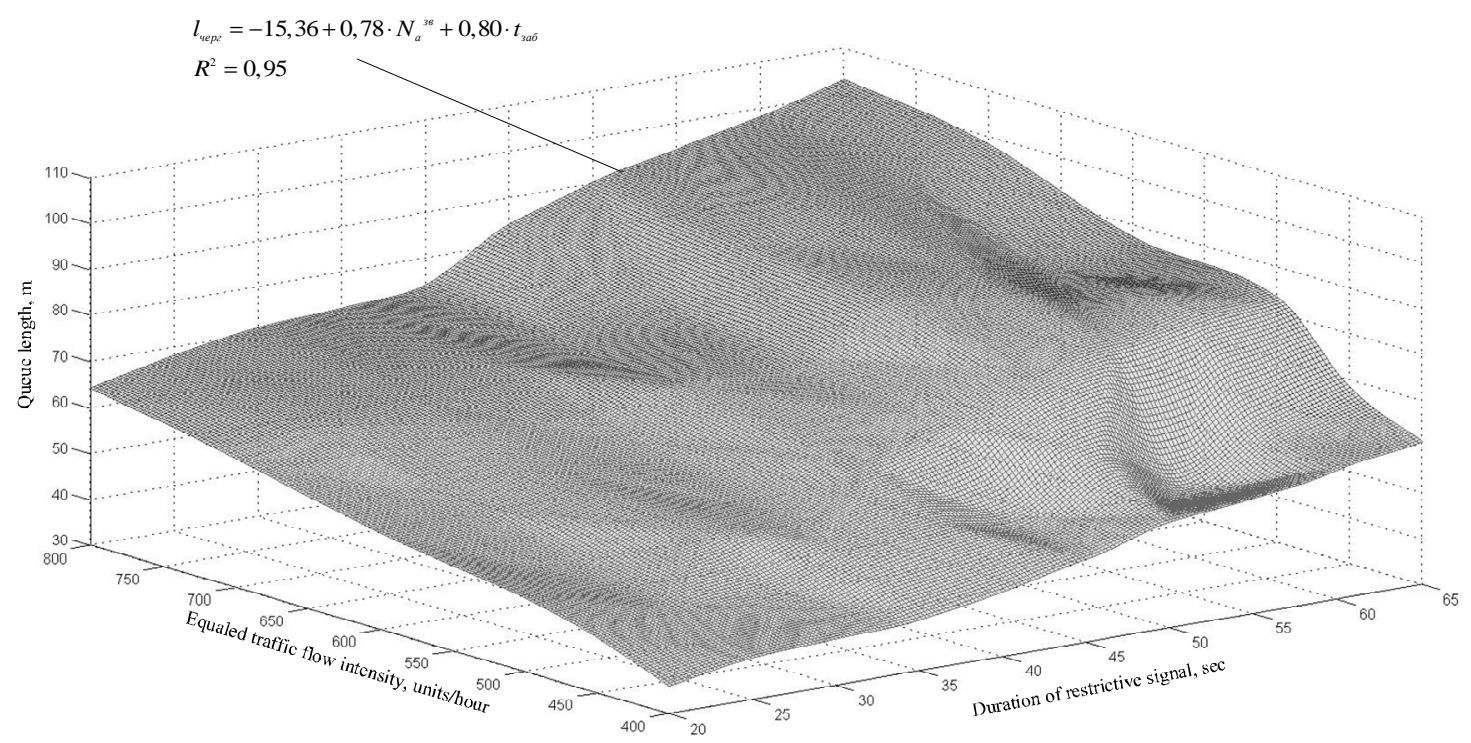

Fig. 6. Simulation results of queue length of vehicles before the stop-line of signaled intersection depending on their intensity and duration of restrictive signal 
Derivation of such regularities is an important stage in designing the regimes of work of traffic light control in city districts with dense construction area and, therefore, small length of street sections between signaled intersections, as it provides opportunity, considering pedestrian and traffic flows intensity and their behavior patterns, to minimize delays on people transportation on the territory of the city.

\section{Conclusions}

Based on results of this study, using methods of field research and traffic simulation, are determined: behavior patterns of pedestrian flows on signaled intersections depending from their primary factors, parameters of pedestrian crossings and regimes of traffic light control; delays of traffic flows before the stop-lines of signaled intersections and their influence on effectiveness of functioning of transport system, as separate city districts, and cities in general. Such research gives an opportunity to improve the level of reliability (road safety) by the way of instant monitoring the factors, which determine road users' behavior, their (factors) adaptive implementation into automated system of traffic control aimed at improvement of their work.

\section{References}

[1] P. G. Buga, Organizatsiya peshehodnogo dvizheniya v gorodah [Organization of pedestrian movement in cities]. Moscow, Russia: Vysshaya shkola Publ., 1980. [in Russian].

[2] A. S. Havaev, "Analiz povedeniya peshehodov pri peresechenii proezzhey chasti" ["Analysis of the behaviour of pedestrians crossing the roadway"], Organization and road safety: Proceedings of the VII All-Russian scientific and practical conference, Tyumen, Russia, April 4, 2014, pp. 62-65. [in Russian].

[3] D. Klebelsberg, Transportnaya psihologiya [Transport psychology]. Moscow, Russia: Transport Publ., 1989. [in Russian].

[4] E. M. Lobanov, Transportnaya planirovka gorodov [Transport urban planning]. Moscow, Russia: Transport Publ., 1990. [in Russian].

[5] Ju. D. Shelkov, Orhanyzatsyia dorozhnoho dvyzhenyia v horodakh [Organization of road traffic in cities]. Moscow, Russia: Transport Publ., 1995. [in Russian].

[6] Ju. A. Vrubel', Poteri v dorozhnom dvizhenii [Losses in road traffic]. Minsk, Bilorus: BNTU Publ., 2003. [in Russian].

[7] G. I. Klinkovshteyn, Organizatsiya dorozhnogo dvizheniya [Traffic Organization]. Moscow, Russia: Transport Publ., 2001. [in Russian].

[8] S. Teply, D.I. Allingham, D.B. Richardson, and B.W. Stephenson, Canadian Capacity Guide for Signalized Intersections. Toronto: Institute of Transportation Engineers, 2008.

[9] V. M. Kysliakov, V. V. Filippov, and I. Ya. Shkoliarenko, Matematycheskoe modelyrovanye y otsenka uslovyi dvyzhenyia avtomobylei $i$ peshokhodov [Mathematical modelling and assessment of the conditions of movement of cars and pedestrians]. Moscow, Russia: Transport Publ., 1979. [in Russian].

[10] D. X. Cheng, Z. Z. Tian, and H. C. Liu, "Implementing actuated signal-controlled intersection capacity analysis with pedestrians", Transportation Research Record, vol. 2071, issue 1, pp. 125-130, 2008.

[11] Q. F. Li, Z. Wang, J. G. Yang, and J. M. Wang, "Pedestrian delay estimation at signalized intersections in developing cities", Transportation Research Part A: Policy and Practice, volume 39, issue1, pp. 61-73, 2005.

[12] M. R. Virkler, "Pedestrian compliance effects on signal delay", Transportation Research Record, vol. 1636, pp. 88-91, 1998.

[13] R. Pretty, "The delay to pedestrians and vehicles at signalized intersection", ITE Journal, vol. 49, no. 5, pp. 20-23, 1979.

[14] Highway Capacity Manual. Washington, DC: TRB Publ, 2000.

[15] Svitlofory dorozhni. Zahalni tekhnichni vymohy, pravyla zastosovuvannia ta vymohy bezpeky [Traffic lights. General technical requirements, application rules and safety requirements], DSTU 4092-02, 2002. [in Ukrainian].

[16] Bezpeka dorozhnoho rukhu. Avtomobilni dorohy, vulytsi ta zaliznychni pereizdy [Road safety. Roads, streets and railroad crossings], DSTU 3587-97, 1997. [in Ukrainian]. 
[17] Avtomobilni dorohy [Roads], DBN 2.3-4:2007, 2007. [in Ukrainian].

[18] Mistobuduvannia. Planuvannia i zabudova miskykh i silskykh poselen [Town planning. Planning and building of urban and rural settlements], DBN 360-92, 2002. [in Ukrainian].

[19] V. A. Cherepanov, Transport v gradostroytelstve [Transport in town planning]. Moscow, Russia: Transport Publ., 1964. [in Russian].

[20] M. S. Fishelson, Transportnaia planyrovka horodov [Transportation planning of cities]. Moscow, Russia: Vysshaya shkola Publ., 1985. [in Russian].

[21] V. G. Sosiants, D. S. Samoilov, and V. A. Yudyn, Bezopasnost dvyzhenyia na horodskom transporte [Safety of traffic on urban transport]. Moscow, Russia: Transport Publ., 1964. [in Russian].

[22] V. A. Vladymyrov, "Vopros orhanyzatsyy dvyzhenyia" ["Questions of traffic organization"], Munitcipalnaia Ekonomika Moskvy [Municipal economy of Moscow], no. 2. pp. 11-13, 1963. [in Russian].

[23] F. V. Webster, and B. M. Cobbe, "Traffic Signals", in Road Research Technical Paper No. 56, London, UK: HMSQ Publ., 1966.

[24] A. G. Levashev, Proektirovanie reguliruemyih peresecheniy [Designing adjustable intersections]. Irkutsk, Russia: IrGTU Publ., 2016. [in Russian].

[25] Yu. A. Kremenets, M. P. Pecherskyi, and M. B. Afanasev, Tekhnycheskye sredstva orhanyzatsyy dorozhnoho dvyzhenyia: uchebnyk dlia vuzov [Technical means of traffic management: a textbook for universities]. Moscow, Russia: Transport Publ., 2005. [in Russian].

[26] V. G. Zhyvohliadov, Teoryia dvyzhenyia transportnykh y peshekhodnykh potokov [Theory of traffic and pedestrian flows]. Rostov-na-Donu, Russia: Izvestiya vuzov. Severo-Kavkazskiy region, 2005. [in Russian]. 